\title{
NOVEL MODULAR NATURAL CIRCULATION BWR DESIGN AND
}

\section{SAFETY EVALUATION}

\author{
Mamoru Ishii ${ }^{\mathrm{a} *}$, Shanbin Shi ${ }^{\mathrm{a}}$, Won Sik Yang ${ }^{\mathrm{a}},{\text { Zeyun } \mathrm{Wu}^{\mathrm{a}} \text {, Somboon Rassame }}^{\mathrm{b}}$, Yang Liu ${ }^{\mathrm{c}}$ \\ ${ }^{a}$ School of Nuclear Engineering, Purdue University, West Lafayette, IN 47907 \\ ${ }^{b}$ Department of Nuclear Engineering, Chulalongkorn University, Bangkok, Thailand 10330 \\ ${ }^{c}$ Department of Mechanical Engineering, Virginia Tech, Blacksburg, VA 24061
}

\begin{abstract}
The Purdue NMR (Novel Modular Reactor) represents a BWR-type small modular reactor with a significantly reduced reactor pressure vessel (RPV) height. Specifically, it has one third the height of a conventional BWR RPV with an electrical output of 50 MWe. The preliminary design of the NMR-50 including reactor, fuel cycle, and safety systems is described and discussed. The improved neutronics design of the NMR-50 extends the fuel cycle length up to 10 years. The NMR-50 is designed with double passive engineering safety system, which is intended to withstand a prolonged station black out with loss of ultimate heat sink accident such as experienced at Fukushima. In order to evaluate the safety features of the NMR-50, two representative design basis accidents, i.e. Main Steam Line Break (MSLB) and Bottom Drain Line Break (BDLB), are simulated by using the best-estimate thermal-hydraulic code RELAP5. The RPV water inventory, containment pressure, and the performance of engineering safety systems are investigated for about 33 hours after the initiation of the accidents.
\end{abstract}


M. Ishii et al. / Novel Modular Natural Circulation BWR Design and Safety Evaluation

Keywords: BWR-type Small Modular Reactor, Long Fuel Cycle Design, Double Passive Safety System, Design Basis Accident Analysis, RELAP5 Simulation

*) Corresponding Author

Mamoru Ishii

School of Nuclear Engineering

Purdue University

West Lafayette, IN, 47907, USA

Tel: +17654944587

Fax: +1 7654945951

Email: ishii@purdue.edu 


\section{ACRONYMS}

\begin{tabular}{|c|c|}
\hline ADS & Automatic Depressurization System \\
\hline $\mathrm{BOC}$ & Beginning of Cycle \\
\hline BDLB & Bottom Drain Line Break \\
\hline BWR & Boiling Water Reactor \\
\hline CAREM & Central Argentina de Elementos Modulares \\
\hline CRDS & Control Rod Drive System \\
\hline DBA & Design Basis Accident \\
\hline DPV & Depressurization Valves \\
\hline DW & Drywell \\
\hline EOC & End of Cycle \\
\hline FWLB & Feedwater Line Break \\
\hline GDCS & Gravity Driven Core Cooling System \\
\hline GenPMAXS & Generation of Purdue Macroscopic Cross Section Set \\
\hline ICS & Isolation Condenser System \\
\hline IMR & Integrated Modular Water Reactor \\
\hline LOCA & Loss of Coolant Accident \\
\hline LWR & Light Water Reactor \\
\hline MCPR & Minimum Critical Power Ratio \\
\hline MSL & Main Steam Line \\
\hline MSLB & Main Steam Line Break \\
\hline NMR & Novel Modular Reactor \\
\hline
\end{tabular}


M. Ishii et al. / Novel Modular Natural Circulation BWR Design and Safety Evaluation

$\begin{array}{ll}\text { PARCS } & \text { Purdue Advanced Reactor Core Simulator } \\ \text { PCCS } & \text { Passive Containment Cooling System } \\ \text { PWR } & \text { Pressurized Water Reactor } \\ \text { RELAP } & \text { Reactor Excursion and Leak Analysis Program } \\ \text { RPV } & \text { Reactor Pressure Vessel } \\ \text { RWCU } & \text { Reactor Water Cleanup } \\ \text { SBWR } & \text { Simplified Boiling Water Reactor } \\ \text { SG } & \text { Steam Generator } \\ \text { SMART } & \text { System-Integrated Modular Advanced Reactor } \\ \text { SMR } & \text { Small Modular Reactor } \\ \text { SP } & \text { Suppression Pool } \\ \text { SRV } & \text { Safety Relief Valves } \\ \text { TAF } & \text { Top of Active Fuel } \\ \text { VV } & \text { Vertical Vent } \\ \text { WW } & \text { Wetwell (Suppression Pool Gas Space) }\end{array}$


M. Ishii et al. / Novel Modular Natural Circulation BWR Design and Safety Evaluation

\section{Introduction}

The development of clean, safe, affordable nuclear energy is a key element to satisfy the increasing electricity demands worldwide in the next decades. Small and medium modular reactors are becoming one of the most promising reactor concepts for developing or under developed countries, especially after the accident at the Fukushima Dai-ichi Nuclear Power Plant in Japan. The benefits of modularity, completely passive safety system, lower capital investment, siting flexibility and non-proliferation characteristic offer greater advantages of SMRs over conventional nuclear reactors.

Small modular reactor (SMR) designs usually are originated from proved and widely used light water reactor (LWR) design, but most SMR designs simplify the reactor system and integrate the passive safety systems and also utilize the natural circulation cooling even under normal operation. SMR designs are being developed in Argentina, Brazil, France, Japan, Republic of Korea, Russia, and the United States of America. These SMR designs (Bae et al., 2001; Hibi et al., 2004; Ingersoll, 2009, 2011; Vujić et al., 2012) include CAREM, IMR, SMART, NuScale, Westinghouse SMR, B\&W mPower. However, all the SMR designs mentioned above are pressurized water reactors (PWR). Compared to the PWR-type of SMR, the BWR-type of SMR can have more simplified design due to the elimination of the secondary loop and steam generators (SGs). As far as the natural circulation driving force is concerned, two phase natural circulation is better than single phase natural circulation, which gives BWR-type SMR another advantage over PWR-type SMR to have a shorter reactor pressure vessel (RPV).

The Purdue NMR (Novel Modular Reactor) represents a BWR-type small modular reactor with a significantly reduced RPV height. Specifically, it has one third the height of a conventional BWR RPV with an electrical output of 50 MWe. NMR-50 core design can achieve up to 10 years of fuel cycle length. The NMR-50 is designed with an improved double passive engineering safety system, which is 
intended to withstand a prolonged station black out with loss of ultimate heat sink accident. Table 1 highlights the safety features and economic performance of the NMR in comparison with other light water reactor SMR designs.

This paper is focused on the preliminary design of NMR including the system design, fuel cycle design, and passive safety systems design. The design parameters and component description are presented. The fuel cycle design for the NMR-50 analyzes the performance of an AREVA BWR Atrium10B type of fuel assembly. The emphasis is placed on the double layers passive safety system of the NMR-50 to withstand against the Fukushima type accident involving prolonged station blackout and loss of ultimate heat sink. Two design basis accidents are simulated by using RELAP5 to study the safety characteristics of the NMR-50.

\section{NMR preliminary design}

\subsection{Design of reactors}

The preliminary design of the NMR-50, including the engineering safety systems, has been based on the reference reactor GE SBWR-600 (GE Nuclear Energy, 1992). Its electrical power is 1/12 that of the SBWR-600. Under steady state at full pressure, the steam flow rate and the coolant mass flow rate in the NMR-50 follow the power ratio. For the design of the NMR-50, two geometrical parameters are important and need to be determined first. These are the height and diameter of the reactor vessel. The NMR-50 only uses one-third the number of fuel assemblies as are used in the SBWR-600. Since the NMR-50 and SBWR-600 use similar configuration of fuel assembly layout, the core cross sectional area and coolant flow area are one third that of the SBWR-600. The core height of the NMR-50 is half that of the SBWR-600 core. The total height of the NMR-50 is $1 / 2.5$ that of the SBWR-600 in the preliminary reactor system design. The NMR-50 is a natural circulation boiling water reactor, and the natural 
M. Ishii et al. / Novel Modular Natural Circulation BWR Design and Safety Evaluation

circulation rate is 1/4 that of the SBWR-600 and is derived from the mass flow rate ratio and area ratio. With all these features concerned, some key design parameters for the NMR-50 for thermal-hydraulic behavior, fuel and other reactor components performance are selected and listed in Table 2.

A preliminary schematic of the NMR-50 is provided in Fig.1. This reactor is suitable for standardized factory manufacturing and assembly. The major components of this reactor are the steel containment, reactor pressure vessel (RPV), passive containment cooling system (PCCS), and isolation condenser system (ICS). The containment is a single steel tank unit with internal compartments for a suppression pool (SP) and vacuum breaker check valve system. The entire containment can be located on a steel reinforced concrete cavity with special padding to isolate seismic ground motion. The cavity provides an additional barrier for contaminated liquid leakage to the environment and a missile shield. Furthermore, the outside containment cavity is designed to be the final back-up safety system for containment cooling in case of PCCS failure or for long-term containment cooling.

\subsection{Fuel cycle design and analyses}

Following standard neutronics analysis methodology for light water reactor (LWR), the code system being employed for the fuel cycle design and analysis on the NMR-50 consists of three principle modules: A lattice code module, CASMO (Edenius et al., 1995), is used to generate few group crosssections; a core simulator, PARCS (Joo et al., 1998; Downar et al., 2009), is employed to perform core calculations and provide flux and power information; and a thermal-hydraulic module, RELAP5 (Siefken et al., 2001), is adopted to provide thermal feedback for PARCS. Figure 2 (Xu and Downar, 2006) depicts the code system used for neutronics analysis and the data flows among the three codes. Here, the GenPMAXS (Generation of Purdue Macroscopic Cross Section Set) functions as an interface between the lattice code and core simulation code. It processes the output files from the CASMO and generates the PMAXS formatted cross section files that can be read by PARCS. 
The fuel cycle design of the NMR-50 is based on design of the SBWR-200, which was studied by Downar and his colleagues (Tinkler and Downar, 2003) and was originated from the GE design of 600 MWe SBWR (GE Nuclear Energy, 1992). In order to achieve the downgraded power rate, the axial height of the core is reduced by half and the radial size is kept unchanged in the NMR-50 design such that the total reactor volume is reduced by half. However, since the total power is reduced by a factor of four (from $660 \mathrm{MW}$ th to $166 \mathrm{MWth}$ ), the power density of the NMR-50 is reduced to be half that of the SBWR-200. Figure 3 shows the radial configuration of the quarter core of the NMR-50, which consists of 64 fuel assemblies and 19 cruciform control rod blades.

The primary fuel design objective of the NMR-50 is to achieve a reliable reactor core with a long time fuel cycle length (targeting at least 10 years). The long time fuel cycle goal can be realized by reducing the power density, increasing fissile inventory, etc. The core design should also satisfy all the safety and material related design constraints. For example the minimum critical power ratio (MCPR), which characterizes the flow boiling crisis (dry-out) in BWR operation, must fall into a safety design criterion in the hot channel. As MCPR is closely related to the peak pin power position, the local peaking factor in the assembly design must be restricted to be less than a certain value. The NMR-50 is envisaged to be a reactor with a once-through fuel cycle, so the excessive reactivity at the beginning of cycle (BOC) is to be larger than that of current BWR core designs to compensate for the fuel depletion for the targeted long fuel cycle. This results in a larger reactivity control requirements of control elements. Another constraint for the fuel design comes from the current nuclear fuel fabrication limitation: at the moment, the fissile enrichment is restricted to be $5 \%$ for normal LWR fuels. Starting from the results of the SBWR-200 calculations (Tinkler and Downar, 2003), a set of design objective and constraints was developed for the NMR-50 fuel assembly design as given in Table 3. The assembly 
M. Ishii et al. / Novel Modular Natural Circulation BWR Design and Safety Evaluation

k-infinity required for the core criticality at the end of cycle (EOC) was conservatively estimated to be 1.06 by taking into account the relatively larger leakage due to short core height.

In order to meet all the NMR-50 fuel design objectives and constraints presented in Table 3, the AREVA Atrium-10B assembly design was chosen and further optimized for NMR-50 through CASMO4 assembly calculations. Figure 4 shows a NMR-50 fuel assembly design based on the AREVA Atrium10B design, which consists of 91 fuel rods laying over a $10 \times 10$ grid with a square-shaped water rod in the middle of the assembly. The color of the fuel rods in the figure denotes different U-235 enrichments. To reduce the local peaking factor in the assembly, 15 Gadolinium enriched burnable poison fuel rods (as shown with red color in the figure) are introduced in the AREVA assembly.

Table 4 compares key design and performance parameters between the NMR-50 assembly and the GE-BP- $8 \times 8$ assembly, which was used in the SBWR-200 and the SBWR-600. In contrast to GE fuel assembly, the NMR-50 assembly based on the AREVA Atrium-10B assembly uses a smaller fuel rod size, but the number of fuel rods is increased from 60 to 91 . As a consequence, the total fuel volume is larger in the NMR-50 assembly, which provides more fissile inventory required for the targeted long fuel cycle. The MCPR associated with each assembly design was calculated using the Hench-Gillis correlation (Hench and Gillis, 1981; Tinkler and Downar, 2003). The MCPR calculated for the NMR-50 is 1.84 for NMR-50 assembly mainly because of the reduced linear power, while it was 1.32 for GE assembly. That is, the NMR-50 assembly exhibits a much larger margin to boiling crisis. It is worthy to note that the MCPR specified as the safety design criterion in GE SSAR (GE Nuclear Energy, 1992) is 1.32 .

\subsection{Safety system design}

The recent Fukushima nuclear accident shows that a fully passive safety system is vitally important to cope with design basis accidents (DBAs) and beyond DBAs. Therefore, two layers of passive safety 
systems are incorporated into the NMR-50 design for adequate removal of decay heat for an indefinite period without outside intervention. The first layer consists of conventional passive safety systems such as an automatic depressurization system (ADS), a passive containment cooling system (PCCS) and an isolation condenser system (ICS). The gravity driven cooling system (GDCS) is eliminated, but this loss is compensated for by increasing the core coolant inventory and simplifying the design. This feature enhances the robustness of the passive safety system. The PCCS is designed for low-pressure operation (less than 1.0 MPa). The ICS is capable of high-pressure operation (up to 7.5 $\mathrm{MPa}$ ) and can act as a decay heat removal system.

The ADS will be actuated at prescribed vessel conditions and depressurizes the reactor vessel so that flashing of the reactor coolant inventory can be used as an effective heat sink for cooling. In the event of low water level in the RPV, the suppression pool water is available to flood the reactor core. These safety systems provide adequate cooling of the reactor vessel and containment for up to 72 hours without AC power. Furthermore, the passive design eliminates the possibility of human errors.

The second layer of passive safety systems includes a passive containment cavity cooling system and a long term cooling water storage pond. When the primary safety system becomes unavailable in a prolonged station blackout or a loss of ultimate heat sink accident, the secondary safety system is activated and the cavity between the steel containment and surrounding concrete shield is flooded with the water from the long term storage pond by gravity. The containment outer wall will then benefit from pool boiling heat removal, providing a long term cooling mode. Given the large volume of long term cooling water relative to the decay power, this system is designed to maintain sufficient reactor core and containment cooling capability for an indefinite period without outside intervention. Therefore, the NMR-50 can withstand a prolonged station blackout and a loss of ultimate heat sink accident. This is extremely important for the deployment of SMRs in remote areas or developing countries where a well- 
M. Ishii et al. / Novel Modular Natural Circulation BWR Design and Safety Evaluation

established infrastructure is not available. The recent Fukushima accident shows that even for conventional nuclear power plants, having such a long term passive safety system can prevent or greatly reduce the possibility of severe accidents caused by unpredictable natural or man-made disasters.

\section{NMR-50 safety evaluation}

\subsection{Design basis accident analysis}

In order to evaluate the performance of the engineered safety features of the NMR-50, an accident analysis model should be developed by using the best-estimate thermal-hydraulic code RELAP5. The RELAP5 has been used for the confirmatory accident analysis using the Purdue integral test facility data for SBWR and ESBWR over many years and its reliability has been relatively well established (Xu et al., 2004; Yang et al., 2011, 2012). Two design basis accidents, i.e. main steam line brake (MSLB) and bottom drain line brake (BDLB), are simulated. For this simulation, the reactor is initially assumed to be at full power and normal operation condition and then the break is initiated. The scenario followed the progression of the accident including reactor scram and ADS actuation.

For the development of the thermal hydraulics analyses of accidents, some major thermalhydraulics issues in relation to DBA conditions are identified. During a loss of coolant accident (LOCA), the control rod drive system (CRDS) shuts down the reactor. The primary function of the ADS is to depressurize the reactor vessel so that core decay heat can be removed through flashing and the discharged energy in the containment (Drywell) is removed to outside atmosphere through the PCCS. The steam vented through the safety relief valves (SRVs) is sent to the SP pool where it is condensed, but the steam vented through the depressurization valves (DPVs) goes to the drywell (DW). During the initial blowdown phase, the DW pressure is controlled by venting steam and noncondensable gases through the horizontal vents into the SP. This venting influences the condition in the gas space in the SP. 
In the later phase of blowdown, venting through the horizontal vents is stopped, and the long-term DW pressure is controlled through the PCCS condensers. Long term core decay heat is removed in the following steps. First, the core energy is removed by boiling water inside RPV and venting steam into the DW through DPVs, which remain open once activated. Heat is removed from the core by natural circulation flow within the vessel. Second, the PCCS transfers energy from the DW to the PCCS/ICS pools by condensing steam from the DW in the PCCS condensers. Third, the PCCS/ICS pools transfer their energy to the atmosphere outside the containment by vaporizing pool water and venting steam. When the above cooling system does not work, there is a back-up system. The residual decay heat can be transferred out to the cavity through the containment wall for infinite long period.

\subsection{RELAP5 model for the NMR-50}

The RELAP5 nodalization diagram for the NMR-50 system modeling is shown in Fig. 5. For computation convenience, the one-dimensional process is used with several independent safety systems lumped into one loop. In this section, the one-dimensional NMR-50 MSLB model is briefly discussed. From the nodalization diagram, the NMR-50 is separated into several distinct sections, such as the RPV, DW, WW, ICS, PCCS.

The RPV is the most crucial part in the NMR-50 modeling. It is designed that the core will never be uncovered under the design basis accidents. Therefore, the accurate prediction of the core inventory is very important. The fuels in the core are grouped into three rings (outer/middle/inner) and divided into several parallel channels. A simple separator model is used with the separator tubes, modeled as stand tubes, connected to a large volume that functioned as a separator. The dryer and the RPV steam dome are modeled as two large pipe volumes.

As Fig. 5 shows, the model of the DW is relatively simple since it is a large volume without heat sources. The upper DW is connected to the RPV by the ADS lines so the steam can be discharged from 
the RPV to the DW. The upper DW is connected to the wetwell (WW) through the horizontal vent lines. The Vertical Vent (VV) (Component 640) and the WW (Component 650) are modeled as two parallel pipes with the same height. Three horizontal venting holes on the VV are modeled as three valves between the VV and the WW. Modeling of the PCCS and the ICS are quite similar because they are similar in function and design. Each unit is composed of supply line, condenser, liquid drain line and gas vent line. PCCS supply lines take steam-air mixture from the DW, while drain lines are connected to RPV and vent lines are connected to the SP. The ADS is composed of four SRV lines and four DPV lines. Two SRV lines and one DPV lines are branched from each main steam line (MSL) and connected to the SP. Two DPVs are connected directly to the RPV at about the elevation of the MSLs. Several trip valves are used to control the function sequence of ADS lines. The LOCA trips are simply listed in Table 5.

This model can be used to simulate all kinds of LOCAs (BDLB, MSLB and FWLB) with modification on the break size and location. In this paper, only MSLB and BDLB tests are discussed as two different types of LOCAs since BDLB is a small size, liquid break flow case and MSLB is a large size, steam break flow case. The transient is triggered by the pipe rupture of the break line, which results in a rapid system pressure drop and coolant loss.

\subsection{Main steam line break LOCA}

MSLB is one of the most typical design basis accidents to investigate the NMR-50 safety performance under the abnormal operation conditions. It is a large break LOCA accident that requires ADS discharging and full functioning of safety systems. The MSLB transient is calculated from steady state (first 1000 seconds) by using RELAP5 up to 33 hours. After the break on one of the main steam line is initiated, coolant inside the RPV quickly flashes and flows out through the break. Critical flow is quickly achieved at the break site and the pressure on the RPV dropped rapidly with activation of ADS. 


\section{Ishii et al. / Novel Modular Natural Circulation BWR Design and Safety Evaluation}

The ADS helps to equalize the pressure in the RPV and the containment. Figure 6 displays the RPV and drywell pressure during the accident. A relatively stable pressure of about $300 \mathrm{kPa}$ is reached between the containment and RPV during the long-term cooling phase. The main steam line break flow is shown in Fig. 7. The break flow increases from $0 \mathrm{~kg} / \mathrm{s}$ to about $90 \mathrm{~kg} / \mathrm{s}$ immediately after the break and then reduces to a small amount in 1000 seconds. The RPV downcomer collapsed water level shown in Fig. 8 indicates the core inventory change. The RPV coolant inventory is a key parameter for reactor safety since the fuel may be damaged if the core is uncovered. In the early blowdown stage of the transient, the downcomer collapsed water level drops due to the main steam line break flow. The core inventory is raised for the remaining period due to the opening of the equalization lines from the suppression pool and PCCS drain flow back to RPV, which are plotted in Fig. 9 and Fig. 10. As can be seen, the downcomer collapsed water level is always above the top of active fuel (TAF), which is $2.367 \mathrm{~m}$. Since the two phase level is significantly higher than collapsed level, we can confidently state that the core remains covered during the entire transient.

\subsection{Bottom drain line break LOCA}

BDLB accident is another design basis small break LOCA in the NMR-50. The RELAP5 analysis simulates the accident scenario in the NMR-50 by introducing the break located at the junction between the bottom drain line (BDL) and the reactor water cleanup (RWCU) line, which are the two valves (components 412 and 424) in Fig.5. The lowest break elevation is considered to be the most serious design basis accident in the NMR-50 design. The BDLB RELAP5 simulation also starts from steady state (first 1000 seconds) and lasts about 33 hours. The RELAP5 simulation results of BDLB are shown from Fig. 11 to Fig. 15. Similar to the MSLB, the ADS actuated immediately after the break initiation. The critical flow occurs and the RPV water level drops below RWCU level. The break flow rate shown in Fig. 12 comes from two break lines. The RWCU line break flow rate is much larger than that in the 
BDL. When the water level is below the RWCU level, the RWCU flow rate drops to zero. And the BDL break flow rate drops to a small amount after 2500 seconds. Figure 13 shows the RPV downcomer collapsed water level. The water level drops quickly after the break and then increases due to opening of the suppression pool equalization line and PCCS drain flow. The water level during BDLB is also always above the TAF. After the SP equalization line open, the system pressure is stabilized and the long-term cooling phase is achieved.

\section{Conclusions}

In this paper, the BWR-type natural circulation small modular reactor NMR is introduced and its characteristics are discussed in comparison with other SMR designs on the market. The NMR is designed to provide electric power to remote areas and developing countries that are deficient in advanced infrastructures. The NMR has simplified design and compact size due to the elimination of the steam generator and the use of two phase natural circulation compared to small modular PWRs.

The preliminary concept of the NMR-50 is similar to the GE SBWR-600 design but significant simplification has been made. Furthermore, it has additional back-up cooling for the containment such that the reactor can stand against accident similar to Fukushima accident where prolonged station black out and loss of heat sink occurred. The application and optimization of AREVA BWR Atrium-10B type of fuel assembly extend fuel cycle length of the NMR-50 to at least 10 years. With respect to the engineering safety systems, the NMR-50 is equipped with two layers of passive systems. The NMR-50 has a set of normal safety system such as ADS, PCCS and ICS etc. The GDCS system is eliminated and compensated by increased core coolant inventory. The second layer of passive containment cavity cooling system can enable the NMR-50 to remove the decay heat without outside intervention for indefinite period during severe accidents. 
The safety features of the NMR-50 are studied by using RELAP5 simulation of two DBA accidents, i.e. MSLB and BDLB. The RELAP5 simulation lasts up to 33 hours for both accidents. The results are similar for two accident simulations. The RPV downcomer collapsed water level is always above the top of active fuel, which protects the core fuel from drying out after the accidents. The ADS system, PCCS, and equalization line etc. function in sequence to the core inventory. The RELAP5 simulation shows that the passive safety system of the NMR-50 provides adequate decay heat removal capability during the accidents.

\section{Acknowledgments}

This material is an extensive of the work supported under a Department of Energy Nuclear Energy University Program. 
M. Ishii et al. / Novel Modular Natural Circulation BWR Design and Safety Evaluation

\section{References}

Bae, K.H., Kim, H.C., Chang, M.H., Sim, S.K., 2001. Safety evaluation of the inherent and passive safety features of the smart design. Ann. Nucl. Energy 28, 333-349.

Downar, T., Xu, Y., Seker, V., 2009. PARCS v3. 0 - US NRC core neutronics simulator user manual (No. UM-NERS-09-0001). Universtiy of Michigan.

Edenius, M., Ekberg, K., Forssén, B.H., Knott, D., 1995. CASMO-4, a fuel assembly burnup program, user's manual. Studsvik0SOA-9501 Studsvik Am. Inc.

GE Nuclear Energy, 1992. SBWR standard safety analysis report. Rep. 25A5113 Revd A.

Hench, J.E., Gillis, J.C., 1981. Correlation of critical heat flux data for application to boiling water reactor conditions. Final report - EPRI-NP-1898.

Hibi, K., Ono, H., Kanagawa, T., 2004. Integrated modular water reactor (IMR) design. Nucl. Eng. Des., 11th International Conference on Nuclear Energy 230, 253-266.

Ingersoll, D.T., 2009. Deliberately small reactors and the second nuclear era. Prog. Nucl. Energy 51, 589-603.

Ingersoll, D.T., 2011. An overview of the safety case for small modular reactors, in: ASME 2011 Small Modular Reactors Symposium. American Society of Mechanical Engineers, pp. 369-373.

Joo, H.G., Barber, D.A., Jiang, G., Downar, T.J., 1998. PARCS (Purdue Advanced Reactor Core Simulator): A multi-dimensional two-group reactor kinetics code based on the nonlinear analytic nodal method. PU/NE-98-26, Purdue University.

Siefken, L.J., Coryell, E.W., Harvego, E.A., Hohorst, J.K., 2001. SCDAP/RELAP5/MOD3. 3 code manual. NUREG/CR-6150, INEL-96.0422, Idaho National Engineering Laboratory, Idaho Falls, ID. 
M. Ishii et al. / Novel Modular Natural Circulation BWR Design and Safety Evaluation

Tinkler, D.R., Downar, T.J., 2003. The neutronics design and analysis of a 200-MW(electric) simplified boiling water reactor core. Nucl. Technol. 142.

Todreas, N.E., Kazimi, M.S., 2011. Nuclear systems volume I: thermal hydraulic fundamentals, second edition. CRC Press.

Vujić, J., Bergmann, R.M., Škoda, R., Miletić, M., 2012. Small modular reactors: simpler, safer, cheaper? 24th Int. Conf. Effic. Cost Optim. Simul. Environ. Impact Energy ECOS 2011 45, 288-295.

Xu, Y., Downar, T., 2006. GenPMAXS code for generating the PARCS cross section interface file PMAXS. Purdue Univ. Sch. Nucl. Eng.

Xu, Y., Ishii, M., Feltus, M.A., 2004. Safety analysis of multiple-failure of passive safety systems in SBWR-1200 SBLOCA. Nucl. Eng. Des., 11th International Conference on Nuclear Energy 230, 107-119.

Yang, J., Choi, S.-W., Lim, J., Lee, D.-Y., Rassame, S., Hibiki, T., Ishii, M., 2011. Scaling, experiment, and code validation on an integral testing facility, in: The 14th International Topical Meeting on Nuclear Reactor Thermalhydraulics. Presented at the NURETH-14, Toronto, Ontario, Canada.

Yang, J., Choi, S.-W., Lim, J., Lee, D.-Y., Rassame, S., Hibiki, T., Ishii, M., 2012. Assessment of performance of BWR passive safety systems in a small break LOCA with integral testing and code simulation. Nucl. Eng. Des. 247, 128-135. 


\section{Captions of Figures}

Fig 1 A schematic of NMR-50 design.

Fig 2 The code system for neutronics analysis on NMR-50.

Fig 3 The schematic view of quarter core of NMR-50.

Fig 4 A schematic view of NMR-50 fuel assembly based on AREVA BWR Atrium-10B.

Fig 5 RELAP5 nodalization for NMR-50 system.

Fig 6 RPV and containment pressure (MSLB).

Fig 7 Break flow (MSLB).

Fig 8 Collapsed water levels in the RPV (MSLB).

Fig 9 PCCS drain flow (MSLB).

Fig 10 Equalization line flow (MSLB).

Fig 11 RPV and containment pressure (BDLB).

Fig 12 Break flow (BDLB).

Fig 13 Collapsed water levels in the RPV (BDLB).

Fig 14 PCCS drain flow (BDLB).

Fig 15 Equalization line flow (BDLB). 
M. Ishii et al. / Novel Modular Natural Circulation BWR Design and Safety Evaluation

\section{Captions of Tables}

Table 1 Characteristics and advantages of NMR.

Table 2 Design parameters for NMR-50.

Table 3 Design objectives and constraints for NMR-50.

Table 4 Design parameters comparison between NMR-50 and GE fuel assembly.

Table 5 NMR-50 model LOCA trips list. 


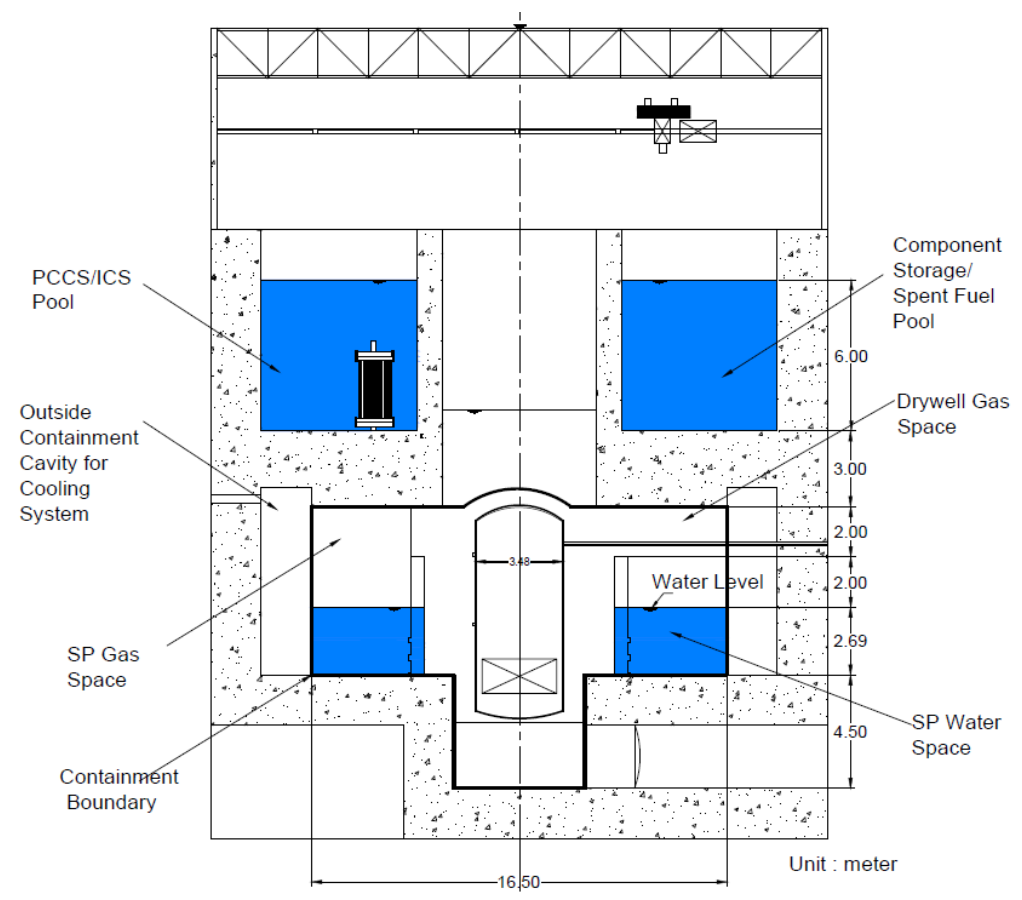

Fig. 1. A schematic of NMR-50 design. 
M. Ishii et al. / Novel Modular Natural Circulation BWR Design and Safety Evaluation

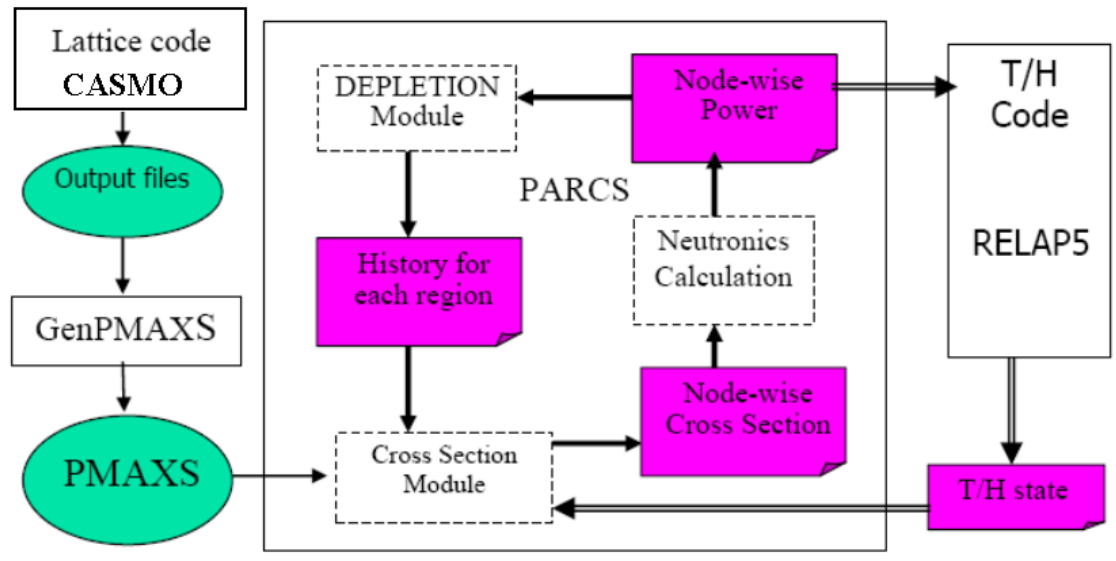

Fig. 2. The code system for neutronics analysis on NMR-50. 
M. Ishii et al. / Novel Modular Natural Circulation BWR Design and Safety Evaluation

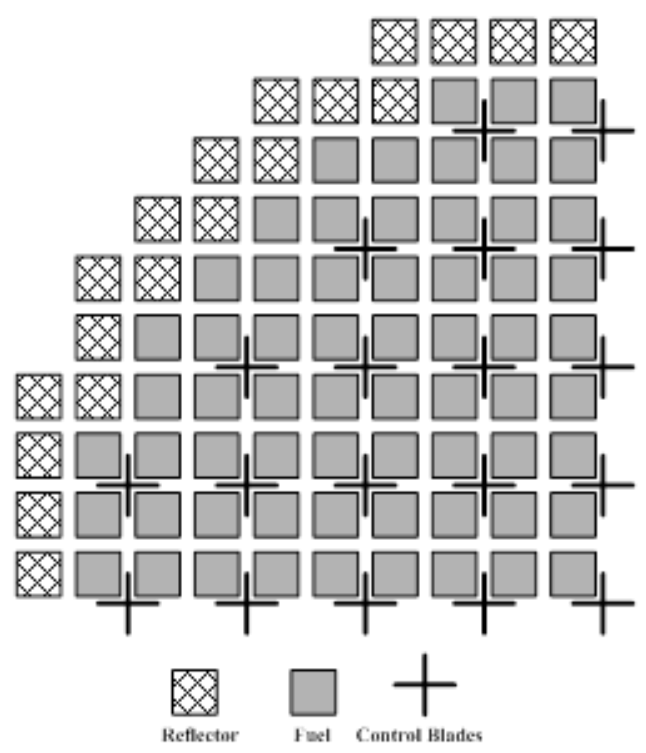

Fig. 3. The schematic view of quarter core of NMR-50. 
Figure 4

M. Ishii et al. / Novel Modular Natural Circulation BWR Design and Safety Evaluation

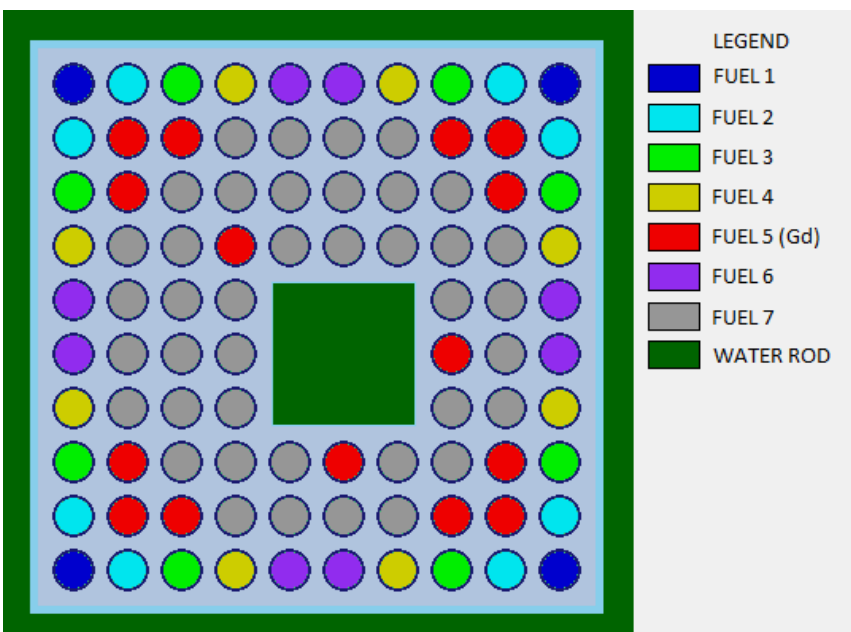

Fig. 4. A schematic view of NMR-50 fuel assembly based on AREVA BWR Atrium-10B. 
M. Ishii et al. / Novel Modular Natural Circulation BWR Design and Safety Evaluation

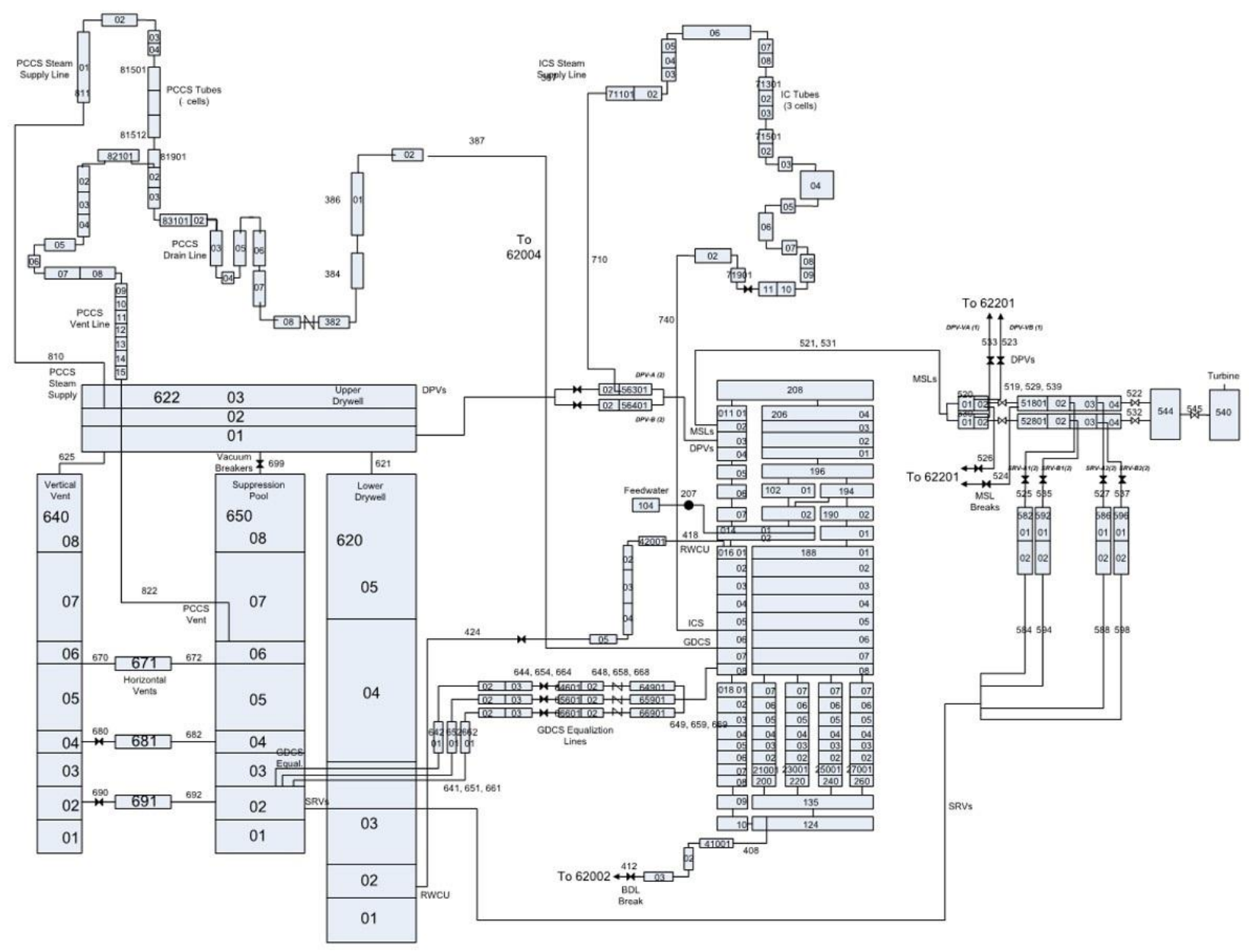

Fig. 5. RELAP5 nodalization for NMR-50 system. 
M. Ishii et al. / Novel Modular Natural Circulation BWR Design and Safety Evaluation

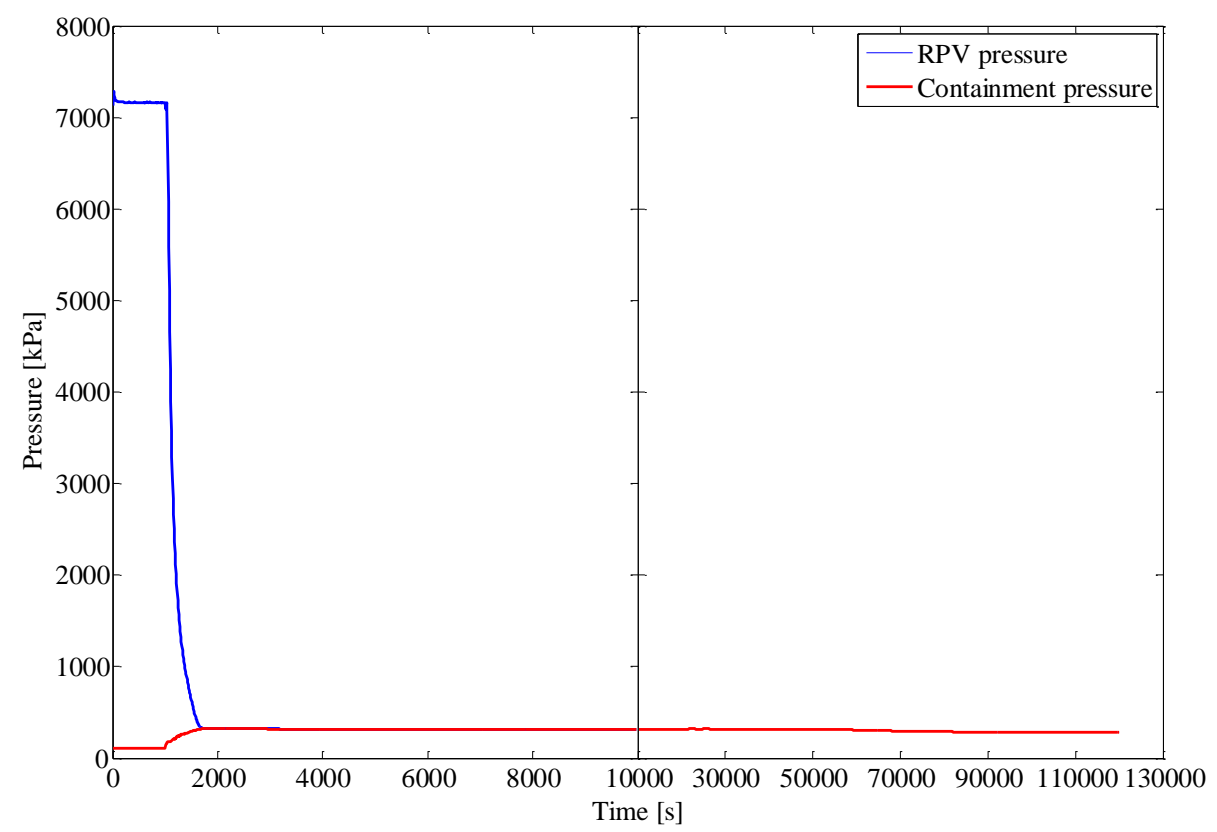

Fig.6. RPV and containment pressure (MSLB). 
M. Ishii et al. / Novel Modular Natural Circulation BWR Design and Safety Evaluation

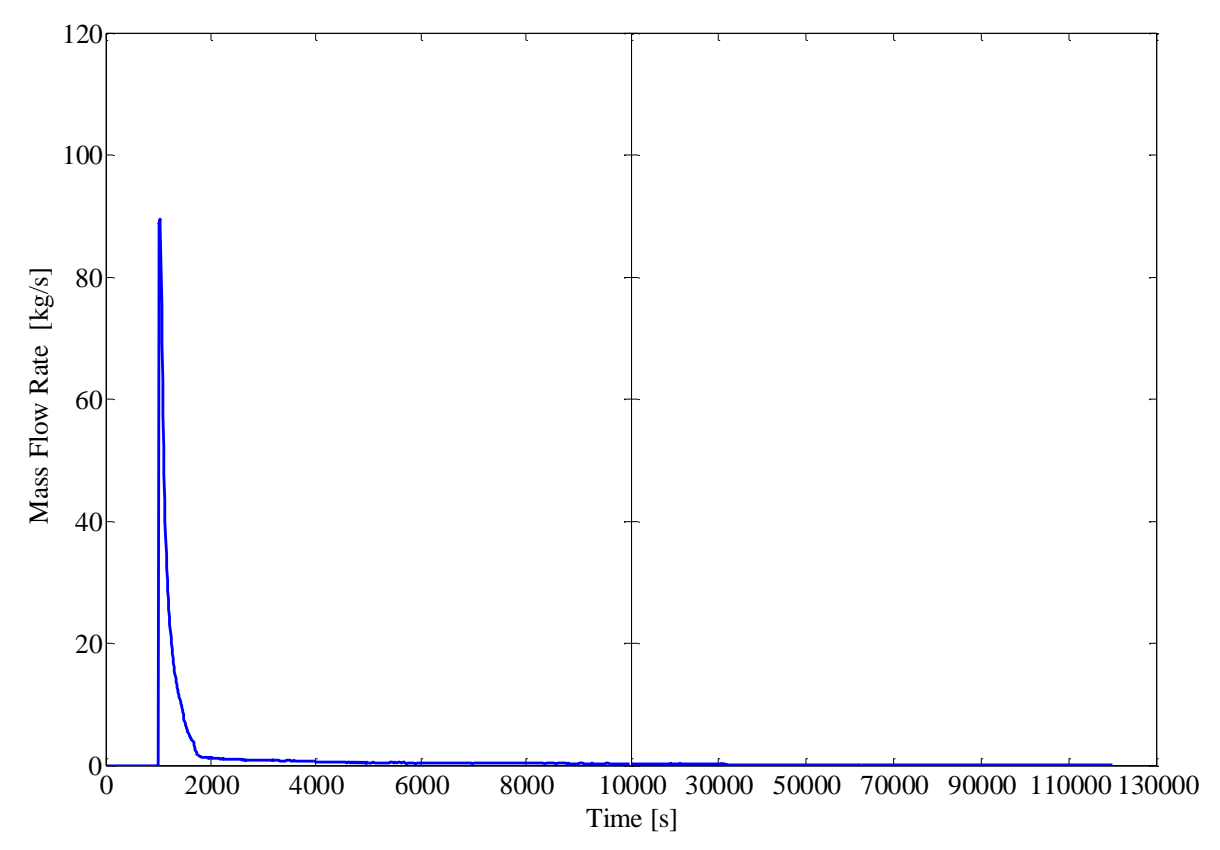

Fig. 7. Break flow (MSLB).

Figure 7 
M. Ishii et al. / Novel Modular Natural Circulation BWR Design and Safety Evaluation

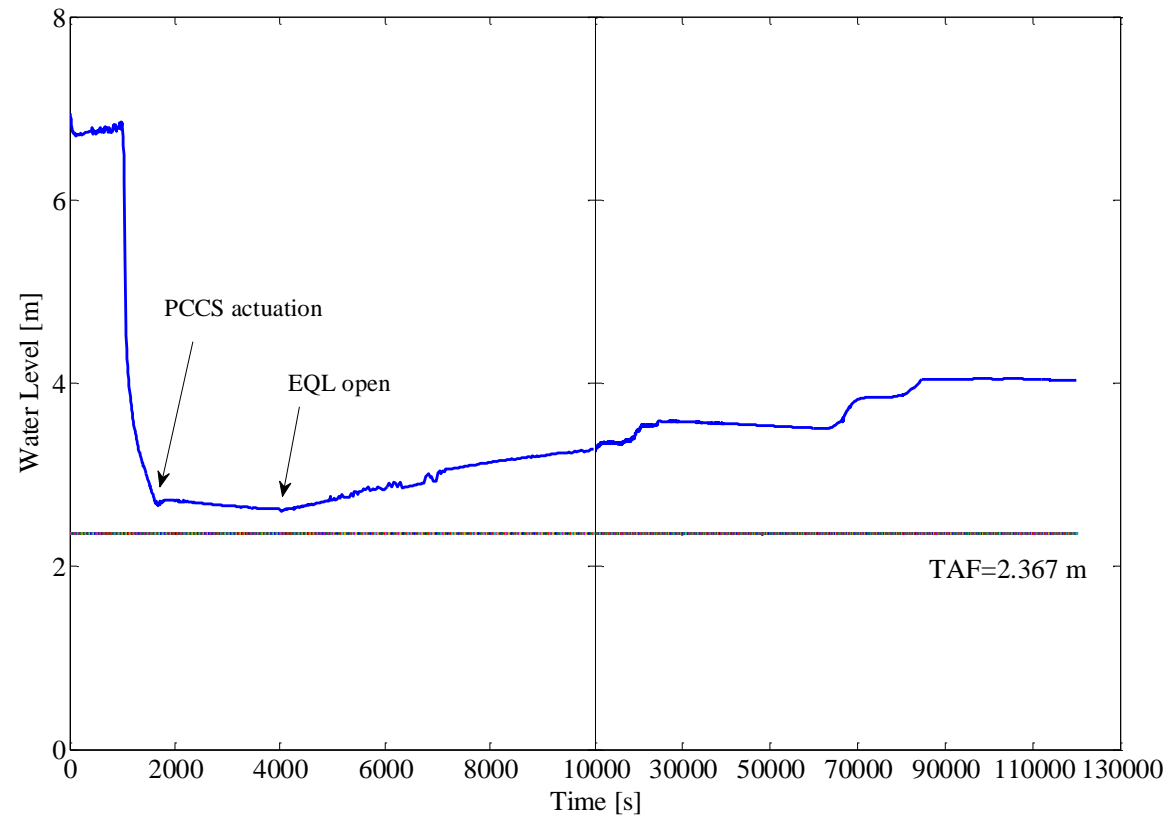

Fig. 8. Collapsed water levels in the RPV (MSLB). 
Figure 9

M. Ishii et al. / Novel Modular Natural Circulation BWR Design and Safety Evaluation

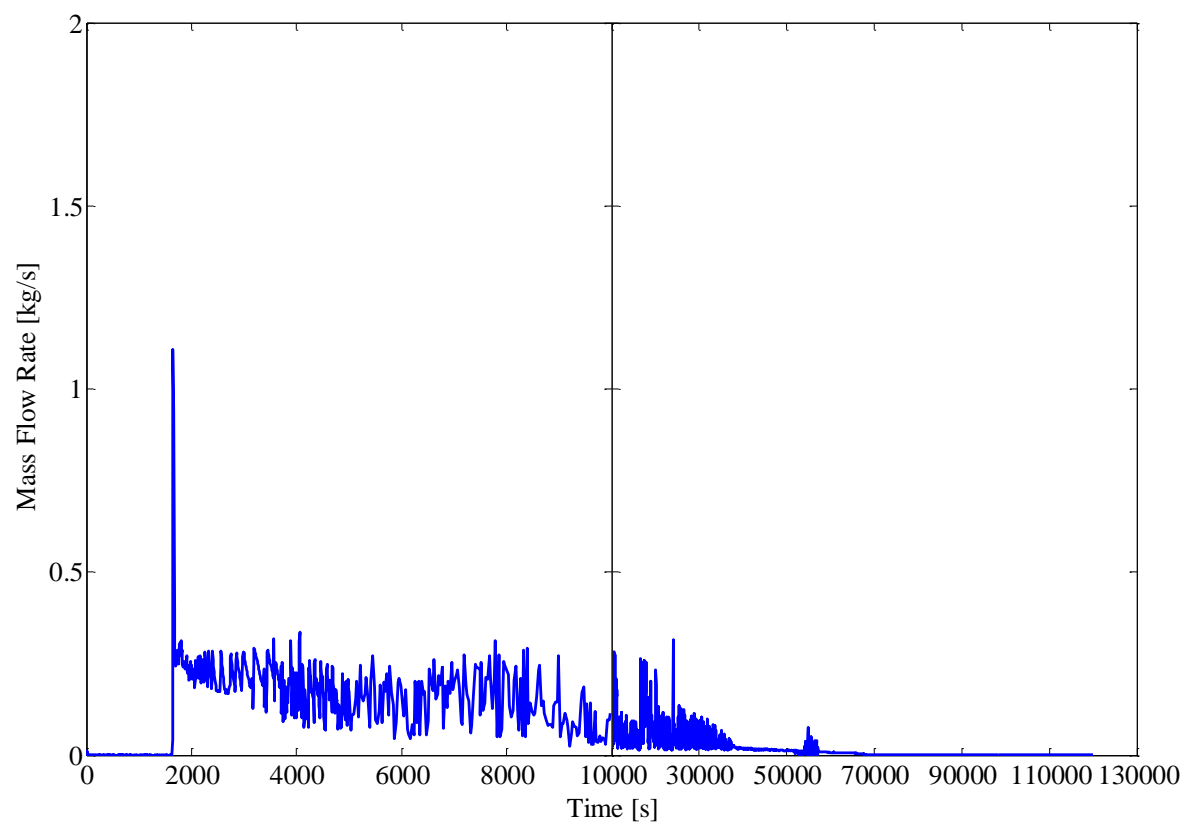

Fig. 9. PCCS drain flow (MSLB). 
M. Ishii et al. / Novel Modular Natural Circulation BWR Design and Safety Evaluation

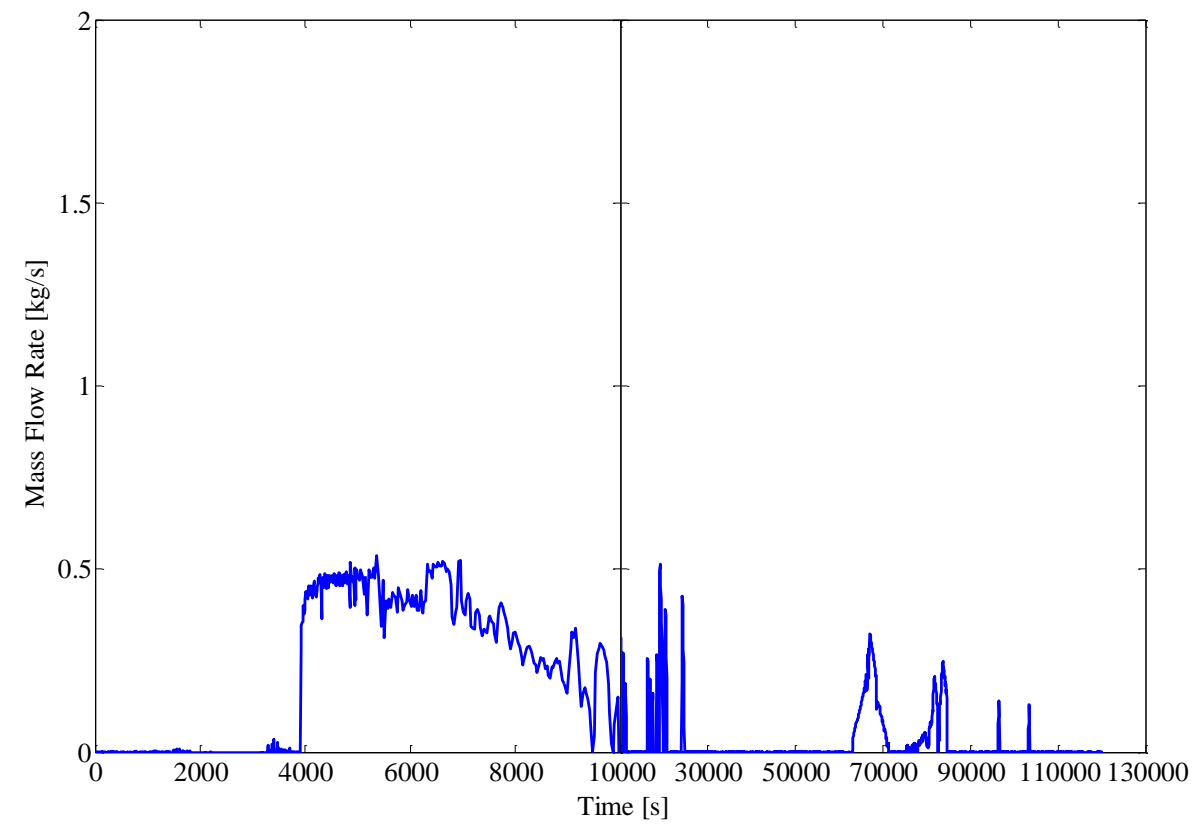

Fig. 10. Equalization line flow (MSLB). 
M. Ishii et al. / Novel Modular Natural Circulation BWR Design and Safety Evaluation

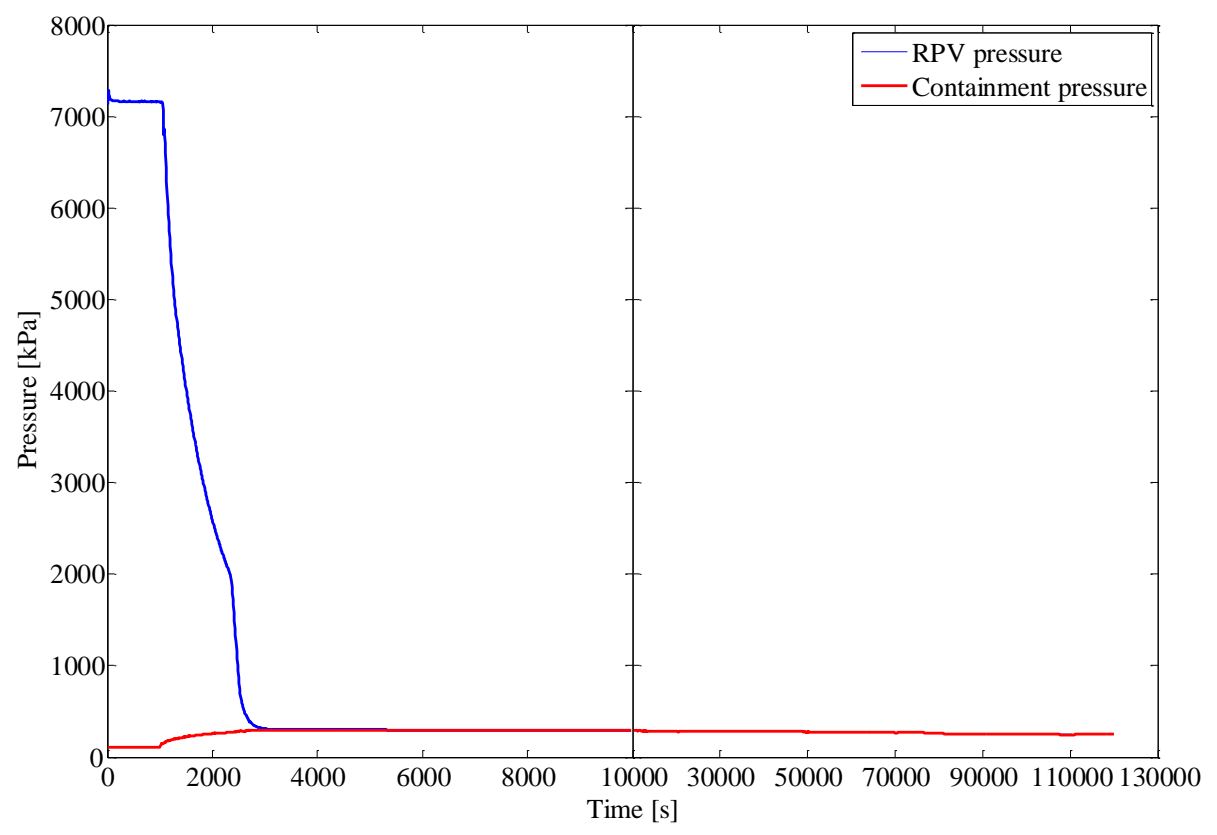

Fig.11. RPV and containment pressure (BDLB). 
M. Ishii et al. / Novel Modular Natural Circulation BWR Design and Safety Evaluation

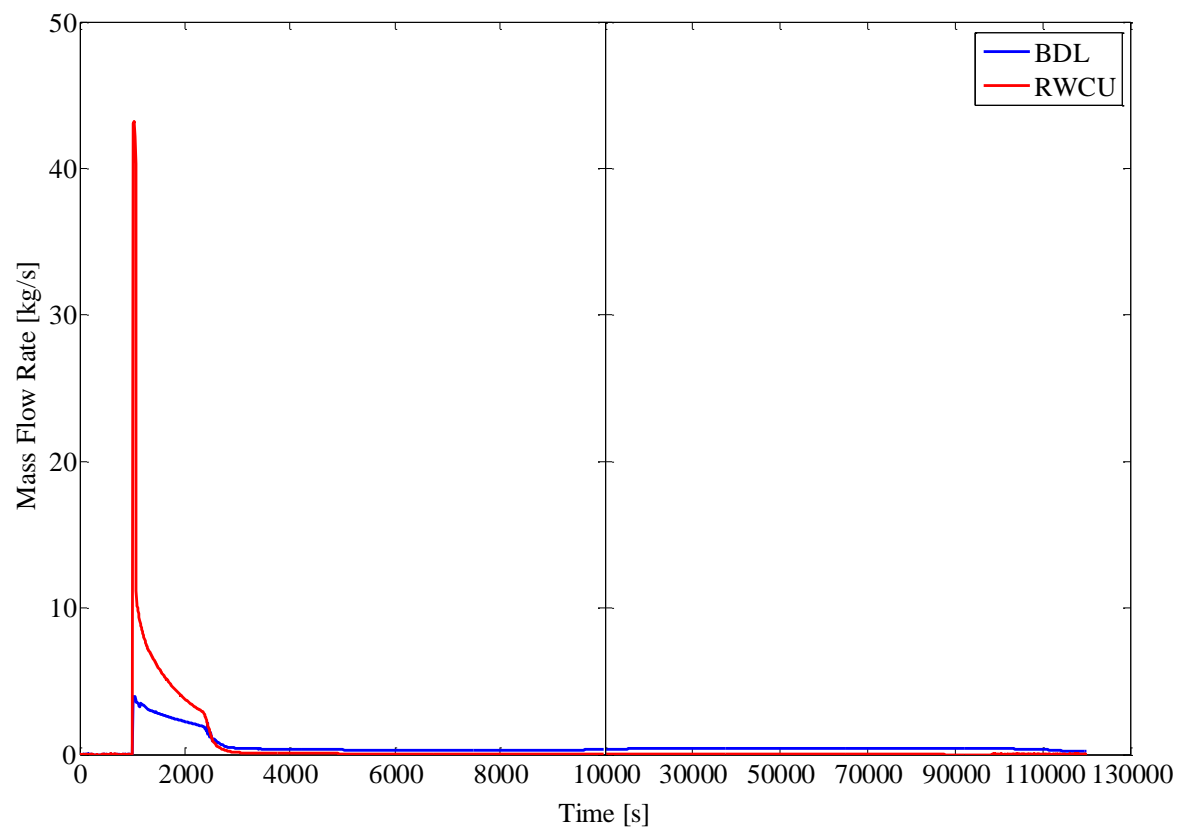

Fig. 12. Break flow (BDLB). 
M. Ishii et al. / Novel Modular Natural Circulation BWR Design and Safety Evaluation

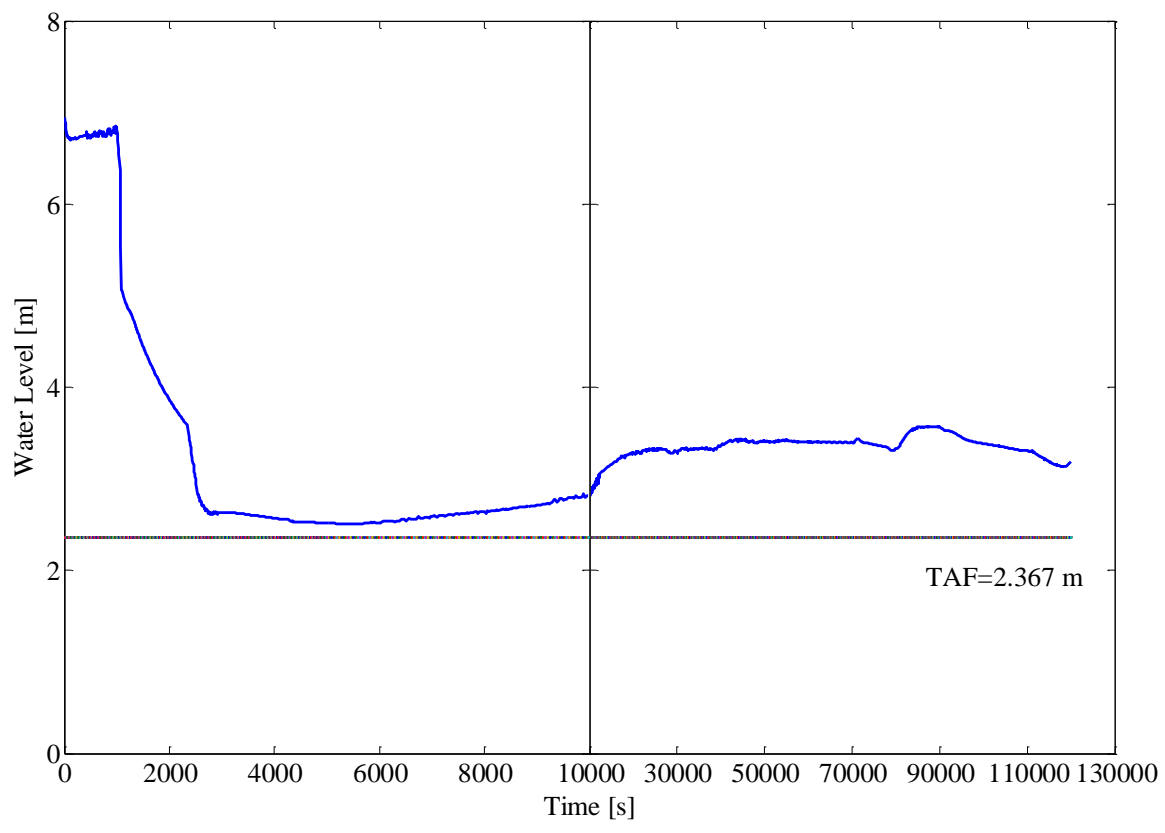

Fig. 13. Collapsed water levels in the RPV (BDLB). 
M. Ishii et al. / Novel Modular Natural Circulation BWR Design and Safety Evaluation

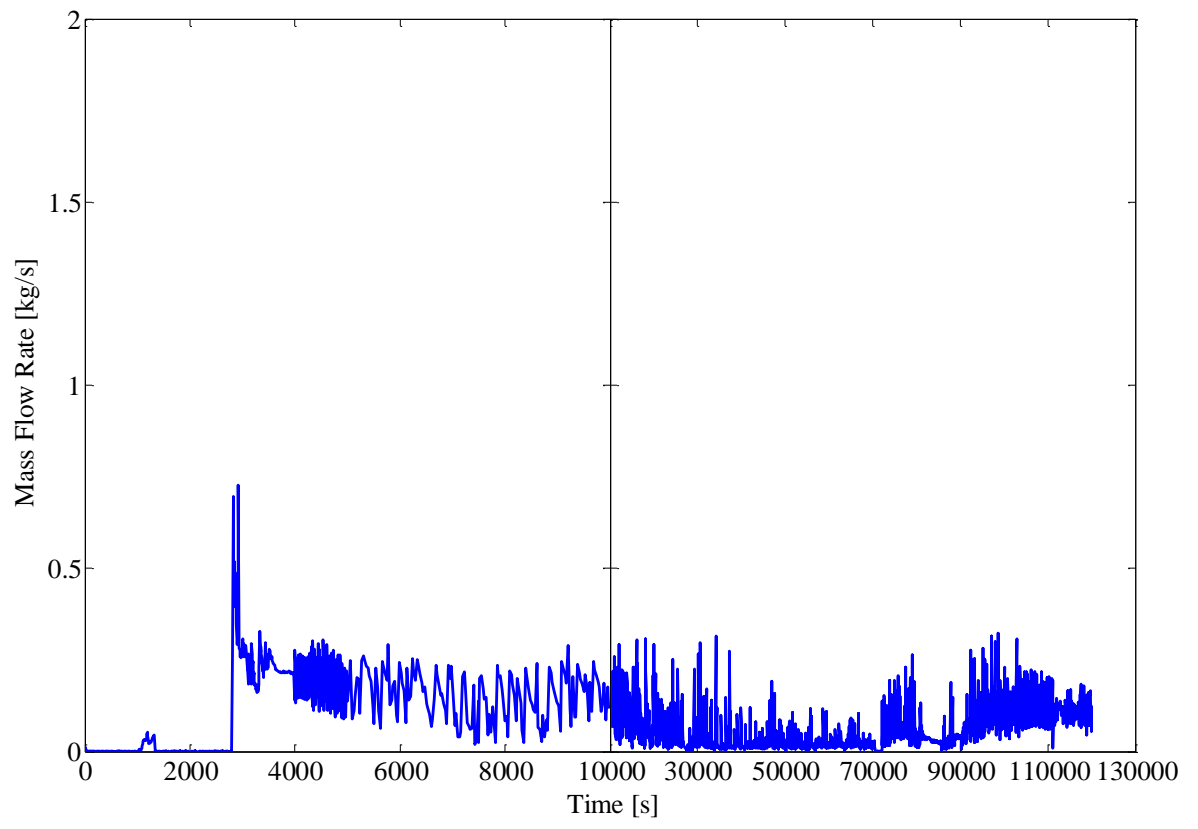

Fig. 14. PCCS drain flow (BDLB). 
M. Ishii et al. / Novel Modular Natural Circulation BWR Design and Safety Evaluation

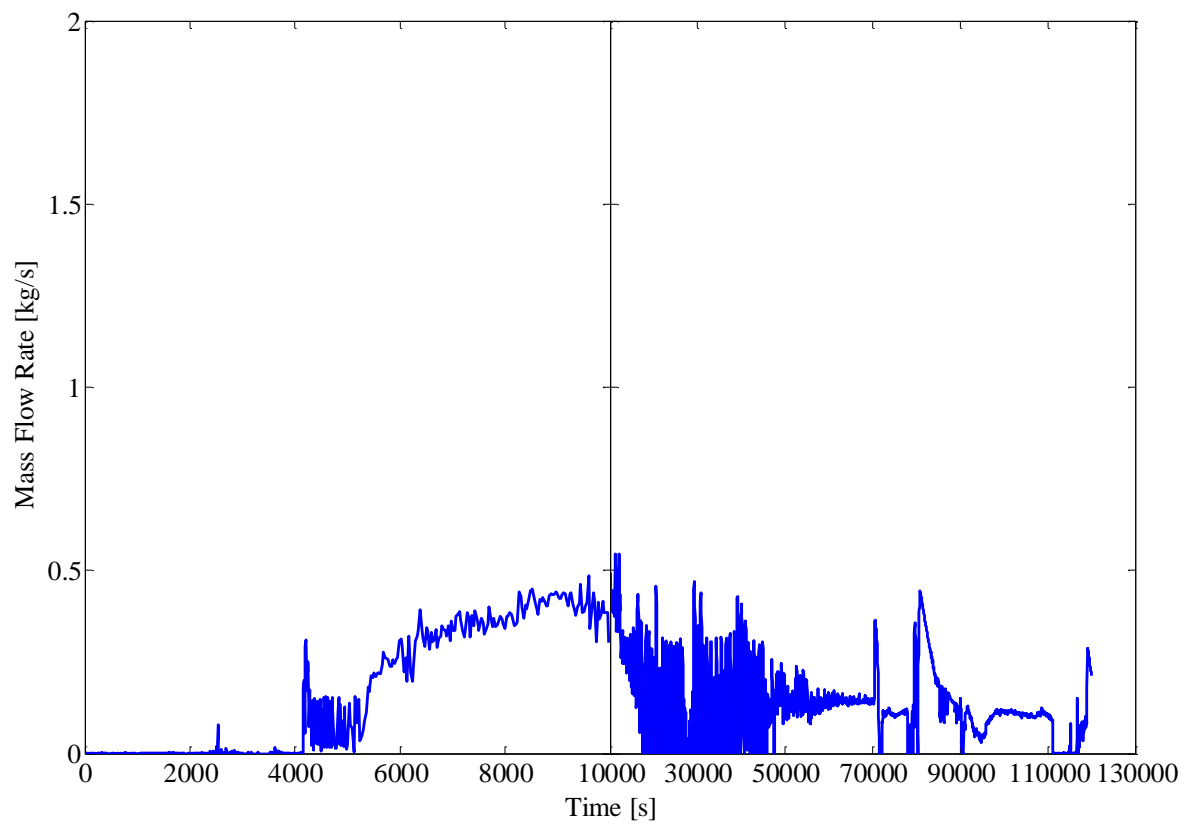

Fig. 15. Equalization line flow (BDLB). 
M. Ishii et al. / Novel Modular Natural Circulation BWR Design and Safety Evaluation

Table 1 Characteristics and advantages of NMR.

\section{Safety}

- Fully passive safety system

- Lower operational pressure

- Lower core power density

- Lower core temperature

- No SG tube failure

- No loss-of-flow accident

- Fewer penetrations on RPV

- Design basis accident management without AC power

\section{Economics}

- Smaller and simpler RPV

- Smaller containment and reactor building

- No need for secondary loop and SGs

- No recirculation and safety pumps

- Direct steam cycle for better efficiency

- Mature BWR technology utilization

- Fewer licensing issues 
Table 2 Design parameters for NMR-50.

\section{Thermal and Hydraulic}

Rated power

$165 \mathrm{MWt}$

Steam flow rate

$319 \mathrm{~kg} / \mathrm{h}$

Core coolant flow rate

$2230 \mathrm{~kg} / \mathrm{h}$

Nominal pressure in steam dome

7.2 $\mathrm{MPa}$

Coolant saturation temperature at core

$288^{\circ} \mathrm{C}$

Average linear heat generation rate

$8 \mathrm{~kW} / \mathrm{m}$

Core average void fraction, active coolant

0.43

Core inlet temperature

$279{ }^{\circ} \mathrm{C}$

Average heat flux

$203 \mathrm{~kW} / \mathrm{m}^{2}$

Core average exit quality

$14.3 \%$

\section{Fuel Assembly}

Number of fuel assemblies

256

Fuel rod array size

$10 \times 10$

Overall fuel length

$1706 \mathrm{~mm}$

\section{Reactor Pressure Vessel}

Total height

$8500 \mathrm{~mm}$

I.D.

$3600 \mathrm{~mm}$

Wall materials

Low alloy steel

Wall thickness

$90 \mathrm{~mm}$

Top of separator tubes

$7230 \mathrm{~mm}$

Bottom of dryer skirt

$6655 \mathrm{~mm}$

Top of dryer skirt

$7970 \mathrm{~mm}$ 
M. Ishii et al. / Novel Modular Natural Circulation BWR Design and Safety Evaluation

Table 3 Design objectives and constraints for NMR-50.

\begin{tabular}{lc}
\hline Fuel cycle length (years) & 10 \\
Local peaking factor & 1.27 \\
k-inf for criticality at EOC & 1.06 \\
Maximum fuel enrichment $(\%)$ & 5.0 \\
\hline
\end{tabular}


Table 4 Design parameters comparison between NMR-50 and GE fuel assembly.

\begin{tabular}{lcc}
\hline Assembly Type & NMR-50 & GE-BP-8 $\times \mathbf{8}$ \\
\hline Fuel rod array layout & $10 \times 10$ & $8 \times 8$ \\
Pitch of square rod array (mm) & 12.954 & 16.200 \\
Fuel rod outside diameter (mm) & 10.55 & 12.27 \\
Fuel rod cladding thickness (mm) & 0.6058 & 0.8126 \\
Pellet-to-cladding gap (mm) & 0.0851 & 0.2032 \\
Fuel density (g/cm ${ }^{3}$ ) & 10.450 & 10.475 \\
Gadolinium (Gd) rods wt\% & 3.5 & 1.8 \\
Cladding material & Zircaloy-2 & Zircaloy-2 \\
Fuel pellet materials & $\mathrm{UO} 2$ & $\mathrm{UO} 2$ \\
Burnable poison & $\mathrm{Gd}$ & $\mathrm{Gd}$ \\
Number of fuel rods per assembly & 91 & 60 \\
Number of water rods per assembly & 9 & 4 \\
Inside channel width (mm) & 134 & 134 \\
Width of channel box wall (mm) & 1.905 & 2.5 \\
Half width of narrow water gap (mm) & 7.264 & 8 \\
Half width of wider water gap (mm) & 7.264 & 8 \\
Fuel Assembly pitch (mm) & 152.4 & 1.32 \\
Operating limit MCPR & 1.84 & \\
\hline
\end{tabular}


M. Ishii et al. / Novel Modular Natural Circulation BWR Design and Safety Evaluation

Table 5 NMR-50 model LOCA trips list.

\begin{tabular}{lll}
\hline Trip No. & Detail & Sequences \\
\hline 001 & Level 1 trip & Level 1 $(3846 \mathrm{~mm}$ from RPV bottom $)$ signal confirmed \\
002 & SRVs open trip & Trip-001 $+10 \mathrm{~s}$ \\
003 & DPVs open trip & Trip-001 $+55 \mathrm{~s}$ \\
004 & EQL open trip & Trip-001 + 1800 s and Level $0.5(2760 \mathrm{~mm})$ confirmed \\
\hline
\end{tabular}

